\title{
Quantitative Amplification of Cleaved Ends (qACE) to assay
}

\section{miRNA-directed target cleavage [version 1; peer review: 3}

\section{approved with reservations]}

\author{
Suresh Damodaran ${ }^{1}$, Sajag Adhikari1 ${ }^{1}$ Marie Turner ${ }^{1,2}$, Senthil Subramanian ${ }^{1}$ \\ ${ }^{1}$ Department of Plant Science, South Dakota State University, Brookings, SD, 57007, USA \\ ${ }^{2}$ Vegenov BBV, Pol de Leon, 29250, France
}

V1 First published: 09 Oct 2014, 3:240

https://doi.org/10.12688/f1000research.5266.1

Latest published: $01 \mathrm{Jul}$ 2015, 3:240

https://doi.org/10.12688/f1000research.5266.2

\begin{abstract}
microRNA (miRNA) regulation is crucial to achieve precise spatiotemporal expression patterns of their target genes. This makes it crucial to determine the levels of cleavage of a particular target mRNA in different tissues and under different conditions. We developed a quantitative PCR method "quantitative Amplification of Cleaved Ends (qACE)" to assay levels of specific cleavage products in order to determine the extent of miRNA regulation for a specific target gene. qACE uses CDNA generated from adapter-ligated RNA molecules and relies on a carefully designed fusion primer that spans the adaptercleaved RNA junction in qPCR to specifically amplify and quantify cleaved products. The levels of full-length transcripts can also be assayed in the same cDNA preparation using primers that span across the miRNA cleavage site. We used qACE to demonstrate that soybean roots over-expressing miR164 had increased levels of target cleavage and that miRNA deficient Arabidopsis thaliana hen 1-1 mutants had reduced levels of target cleavage. We used qACE to discover that differential cleavage by miR164 in nodule vs. adjacent root tissue contributed to nodule-specific expression of NAC1 transcription factors in soybean. These experiments show that qACE can be used to discover and demonstrate differential cleavage by miRNAs to achieve specific spatio-temporal expression of target genes in plants.
\end{abstract}

Keywords

microRNA, degradome, PARE, mRNA cleavage, Glycine max, Arabidopsis thaliana, qPCR, qACE

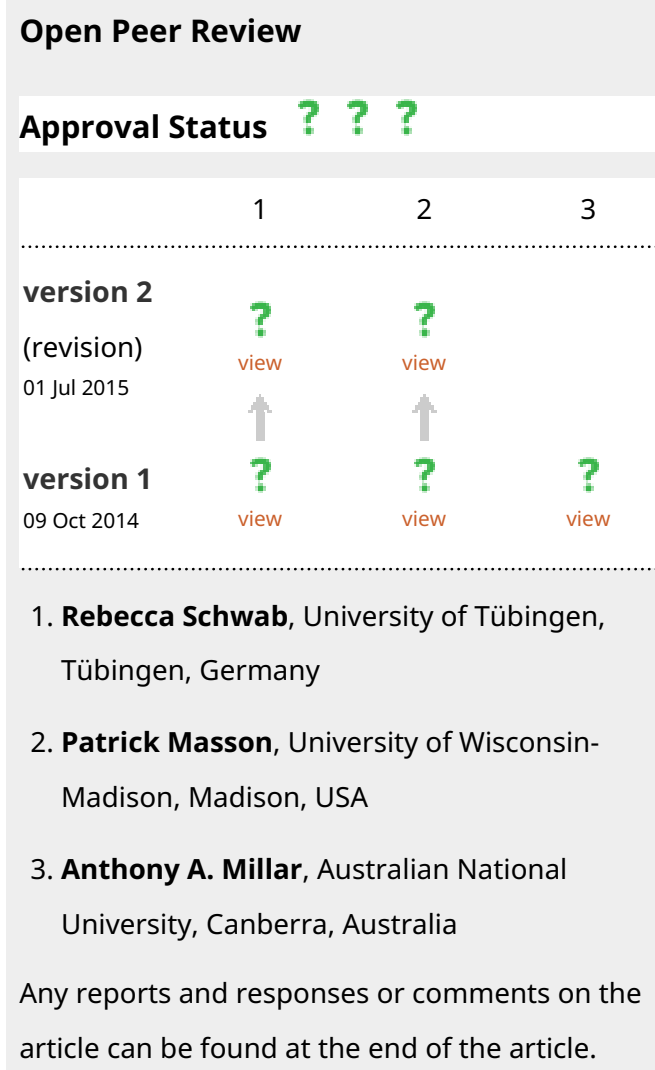

1. Rebecca Schwab, University of Tübingen, Tübingen, Germany

2. Patrick Masson, University of WisconsinMadison, Madison, USA

3. Anthony A. Millar, Australian National University, Canberra, Australia Any reports and responses or comments on the article can be found at the end of the article. 
Corresponding author: Senthil Subramanian (senthil.subramanian@sdstate.edu)

Competing interests: No competing interests were disclosed.

Grant information: Research in the authors' laboratory is supported by funds (awarded to S.S) from USDA-AFRI (2010-65116 20514), NSF-PGRP (IOS-1350189), South Dakota Soybean Research and Promotion Council and South Dakota State University and Agricultural Experiment station.

The funders had no role in study design, data collection and analysis, decision to publish, or preparation of the manuscript.

Copyright: @ 2014 Damodaran S et al. This is an open access article distributed under the terms of the Creative Commons Attribution License, which permits unrestricted use, distribution, and reproduction in any medium, provided the original work is properly cited. Data associated with the article are available under the terms of the Creative Commons Zero "No rights reserved" data waiver (CC0 1.0 Public domain dedication).

How to cite this article: Damodaran S, Adhikari S, Turner M and Subramanian S. Quantitative Amplification of Cleaved Ends (qACE) to assay miRNA-directed target cleavage [version 1; peer review: 3 approved with reservations] F1000Research 2014, 3:240

https://doi.org/10.12688/f1000research.5266.1

First published: 09 Oct 2014, 3:240 https://doi.org/10.12688/f1000research.5266.1 


\section{Introduction}

miRNAs are short 21-22nt RNA molecules that regulate the expression of cognate target genes primarily through post-transcriptional mechanisms ${ }^{1}$. The majority of miRNAs fine-tune target gene expression to achieve proper spatio-temporal expression patterns during plant development as well as in response to environmental changes ${ }^{2-4}$. Adaxial localization of transcripts encoding a set of HD-ZIP III transcription factors by miR166 in leaves ${ }^{5,6}$ is an excellent example. The expression of miR166 is restricted to abaxial layers in contrast to its target genes ${ }^{7}$. Mutations in miRNA recognition sites of HD-ZIP III genes (conferring resistance against miR166mediated decay) resulted in ectopic expression of these genes in abaxial cell layers leading to adaxialized leaves ${ }^{8}$. Polarized expression of miR166 and its target HD-ZIP IIIs is conserved in other plant species as well, e.g. maize ${ }^{7}$, and soybean ${ }^{9}$. Another example is the nodule-meristem specific expression of MtHAP2-1 (alpha subunit of a CCAAT-binding NFY), which is spatially restricted by miR169, which is expressed in the infection zone adjacent to the meristem. Expression of a miRNA resistant MtHAP2-1 under the control of its native promoter led to significantly reduced nodule growth suggesting that spatially restricted expression of MtHAP2-1 is crucial for proper nodule development ${ }^{10}$. Similarly, miR399 plays an important role during inorganic phosphate $(\mathrm{Pi})$ starvation by down regulating $\mathrm{PHO} 2 / \mathrm{UBC} 24$ (a gene encoding a putative ubiquitin conjugating enzyme) mRNA ${ }^{11}$. PHO2 maintains proper levels of phosphate transporter activities ${ }^{12}$ and its down regulation increases phosphate acquisition. These examples demonstrate that mere transcriptional regulation is not sufficient to achieve proper spatial and temporal expression of target genes and miRNA regulation is crucial for additional fine-tuning of gene expression.

Identification, validation and quantification of the extent of regulation of specific target genes by miRNA is crucial for proper understanding of their biological roles. Bioinformatics-based prediction of miRNA targets was developed based on the extent of base-pairing between miRNAs and their targets ${ }^{13}$ and subsequently improved based on base-pairing in specific "seed" regions as well as the cleavage site ${ }^{11,14}$. A defining feature of miRNA-guided regulation in plants is that cleavage takes place precisely between $10^{\text {th }}$ and

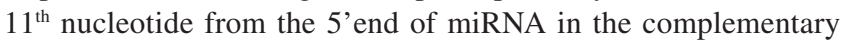
region of the target transcript. A modified RNA Ligase Mediated5'Rapid Amplification of cDNA Ends (RLM-5'RACE) method is being used to validate cleavage by miRNAs by mapping the site of cleavage $\mathrm{e}^{15}$. In this technique an RNA oligo of known sequence is ligated to the mRNA molecules that had an uncapped 5'end arising due to RNase cleavage. OligodT-primed cDNA molecules from adapter ligated RNA is then used to amplify specific target RNA molecules (using a forward primer from the adapter and genespecific reverse primer). Subsequent sequencing of these amplicons can precisely map the cleavage site. This technique serves as an excellent qualitative method to validate miRNA-mediated cleavage of targets. However, this method cannot quantify the extent of miRNA cleavage i.e. increased cleavage in specific tissue types and/or specific developmental stages/time points. In addition, among the multiple targets of a particular miRNA, some are cleaved more efficiently than the others for example, miR393 mediated reduction in the flag22 elicited wild type seedlings, showed reduction of TIR1, AFB2, AFB3 but not AFB $1^{16}$. Recently, high throughput sequencing-enabled methods were developed for genome-wide validation (and identification) of miRNA targets ("degradome" or PARE (Parallel Analysis of RNA Ends)) ${ }^{17,18}$. Briefly, an RNA adaptor with a MmeI recognition site is ligated to the cleaved ends of polyA RNA molecules. Ligated molecules are reverse-transcribed, amplified linearly and digested with MmeI (which cleaves 20 nucleotides (nt) away from the recognition site) yielding short DNA molecules corresponding to the junction of the RNA adapter and miRNA-cleavage end. A dsDNA oligo adapter is subsequently ligated to the MmeI end and these molecules are linearly amplified, and sequenced using high throughput methods. This results in $\sim 20$ nt cleavage signatures that can be used to map miRNA-directed cleavage sites (e.g. CleaveLand bioinformatics pipeline (AddoQuaye et al. 2009). Normalized abundance of cleavage signatures from specific target genes can be used to quantify miRNA-directed cleavage. However, miRNA binding sites of target genes are highly conserved. Therefore, these short signature sequences generated by degradome/PARE analyses might be shared by more than one gene making it impossible to distinguish cleavage levels of specific target transcripts. For example, at least two targets of miR319 share the same cleavage signature in Arabidopsis (Table S1). Other examples include targets of miR161 and miR172. This is especially significant in species with extensive genome duplications (e.g. soybean) and polyploidy species (e.g. wheat) that have a number of paralogs with high sequence identity. For instance, in soybean five auxin response factor (ARF) genes targeted by miR160 shared the same cleavage signature in the degradome library and RLM-5'RACE had to be used to confirm cleavage of individual target genes ${ }^{19}$. In addition, degradome/PARE analysis is a global analysis method and does not allow determining cleavage levels of a small set of miRNA targets (Table S1). A semi-quantitative method to assay miRNA-directed cleavage was reported by Schwab et al. (2005) ${ }^{14}$. However, the method was not widely used subsequently perhaps due to the lack of validation under different conditions and/or its semi-quantitative nature. We enhanced this method through the use of qPCR and named it "quantitative Amplification of Cleaved Ends" (qACE), and evaluated its ability to assay the extent of miRNA-directed cleavage of specific target genes. qACE allows quantification of specific target mRNA molecules resulting from miRNA-directed cleavage in different tissue-types and/or under different experimental conditions. We demonstrate the applicability of this method to (i) assay increased cleavage of targets in miRNA over-expressing plants, (ii) assay reduced cleavage of targets in miRNA-deficient plants, and (iii) to identify a key role for miR164 in conferring nodule-enriched expression of two of its target genes.

\section{Materials and methods}

Plant material

Arabidopsis thaliana wild type Ler and hen 1-1 mutant seeds (obtained from ABRC, Columbus, OH: Stock\#CS6583) were surface-sterilized and grown in Sunshine mix \#1 (Tessman Company, Sioux Falls, SD) under $16 \mathrm{~h}$ light at $25^{\circ} \mathrm{C}$. Leaf, stem and flower tissues were harvested at the same developmental stages, immediately frozen in liquid $\mathrm{N}_{2}$ and stored at $-70^{\circ} \mathrm{C}$. Soybean seeds Glycine max cv. Williams-82, the genotype used for genome sequencing project ${ }^{20}$ were surface-sterilized ${ }^{21}$ and germinated in 4 " pots filled with a mixture of vermiculite: perlite (Hummert International, MO) in the ratio of $1: 3$ and watered with nitrogen free plant nutrient solution ${ }^{22}$. 
The plants were grown in a controlled environment vertical growth chamber (Conviron Growth chamber, Manitoba, Canada). Growth conditions used were: $16 \mathrm{~h}$ light and $8 \mathrm{~h}$ dark and $50 \%$ relative humidity with a day and night temperature of $25^{\circ} \mathrm{C}$ and $20^{\circ} \mathrm{C}$ respectively. For nodulation assays 5 days old germinated plants were inoculated with Bradyrhizobium japonicum (USDA110) grown in Vincent's rich medium prepared and supplemented with Chloramphenicol (antibiotic selection marker) at $30^{\circ} \mathrm{C}^{23}$. The plants were inoculated with $B$. japonicum at a concentration of $\mathrm{OD}_{600}=0.08$ and 14 days post inoculation mature nodules and the root segment adjacent to the nodule were harvested separately.

\section{Over expression of gma-miR164a}

To over-express miR164, the precursor of gma-miR164 (miRBaseID MI0007209) was PCR amplified using G. max genomic DNA as template. The PCR product was initially cloned in to an entry vector PCR8/GW/TOPO (Invitrogen, Carlsbad, CA) and subsequently in to the binary vector pCAMGFP-CsVMV: $\mathrm{GW}^{24}$ using a Gateway LR clonase (Invitrogen, Carlsbad, CA) reaction. The vector was transformed in to Agrobacterium rhizogenes K599 cells, using electroporation and composite plant transformation was performed as described ${ }^{25}$. Transgenic GFP roots were collected on dry-ice and stored at $-70^{\circ} \mathrm{C}$.

\section{RNA isolation and cDNA synthesis}

Total RNA was isolated from the different tissues using TRI reagent (Product\#T9424, Sigma Aldrich, St. Louis, MO) as described previously $^{21}$. The RNA was quantified using Nanodrop spectrophotometer (ND1000, Thermo Scientific, Wilmington, DE) and RNA integrity was verified using agarose gel electrophoresis. Adapter ligated cDNA was prepared using GeneRacer kit (Product\#L1502-01, Invitrogen, Carlsbad, CA) as per the manufacturer's instructions except that calf intestinal phosphatase treatment to remove 5' phosphate and 5' Cap removal using tobacco acid pyrophosphatase steps were omitted. For Arabidopsis gene expression analysis $2 \mu \mathrm{g}$ of total RNA each of leaf, stem, and flower was pooled together and subject to adapter-ligated cDNA synthesis. For gene expression analysis in soybean $7 \mu \mathrm{g}$ of total RNA was used in adapter-ligated cDNA synthesis. For miRNA stem-loop cDNA synthesis, $1 \mu \mathrm{g}$ of total RNA was used and a multiplexed cDNA was performed for all miRNAs examined using M-MuLV reverse transcriptase ${ }^{26,27}$. miR1515 \& U6 was used as normalization/house-keeping control for miRNAs ${ }^{20,28}$.

\section{qPCR and qACE assays}

qPCR assays were performed in MX3000P thermocycler (Stratagene/ Agilent technologies, Santa Clara, CA) using SYBR Advantage qPCR premix (Product\#639676, Clontech, Mountain View, CA). The data was analyzed using the MxPro software. Relative expression values for full length transcripts were performed using the $\mathrm{dCt}$ method $^{29}$ using Actin for soybean and U6 for Arabidopsis as normalization control. Relative levels of cleaved transcripts (described as RCT in text) were calculated using the $\mathrm{dCt}$ method comparing the $\mathrm{Ct}$ values of full-length vs. cleaved transcripts in the same sample. For statistical analyses, we calculated the range of possible expression values in each sample based on the deviation between $\mathrm{Ct}$ values of replicates. Error bars indicate this range in each sample.

\section{Results}

Principle of qACE

qACE is an extension of the modified RLM-5'RACE method ${ }^{15,30}$ used to qualitatively validate target cleavage and the subsequent semi-quantitative method ${ }^{14}$ used to examine the levels of cleavage remnants. An RNA adapter is ligated to cleaved 5'-ends of polyA or total RNA preparations ("adapter-ligated RNA"). The adapter gets ligated to any available 5'-phosphate of ribose molecule of RNA arising due to miRNA-directed cleavage or other means (e.g. mRNA degradation), but not to full-length mRNAs, because of the 5-methyl Guanosine/CAP. Oligo-dT primed cDNAs generated from adapter-ligated RNA are subject to real-time PCR where a primer that spans the adapter junction is used as a forward primer (subsequently referred to as qACE forward primer) and a genespecific reverse primer (Figure 1). The 5'end of the qACE forward primer corresponds to the adapter and the last six nucleotides correspond to the target sequence downstream of the cleavage site (See Discussion for additional details). We expected that the qACE forward primer combined with a gene-specific reverse primer would help specifically amplify ligation products where the adapter is ligated to the predicted/validated cleavage site. Therefore, a qPCR assay using these primers will specifically quantify cleaved mRNAs resulting from miRNA-directed cleavage. We also expected that the qACE forward primer will not amplify full-length cDNA molecules and neither would it efficiently amplify ligation products where the cleaved end does not correspond to the miRNA-directed cleavage site (Figure S4a1). Finally, we also expected that the use of a genespecific reverse primer would amplify linearly and help distinguish different targets of the same miRNA even if the miRNA-binding sites are identical/highly conserved (Figure S4a-d). In addition, the same cDNA preparation can be used to quantify full-length molecules of target mRNA as well as using appropriate primers that span across the miRNA binding site (subsequently referred to as fulllength qPCR primers). Ratio of cleaved transcripts vs. full-length transcripts will serve as a quantitative indicator of the extent of miRNA-directed cleavage of the target mRNA. The level of cleaved target transcripts also depends on the levels of transcriptional activity of the target gene. Therefore, comparing absolute levels of cleaved transcripts (or levels normalized to house-keeping genes) between two conditions or tissue types might not reveal differences in miRNA regulation. We decided to normalize the levels of cleaved transcripts to full-length transcripts using the $\mathrm{dCt}$ method to obtain the ratio of cleaved transcripts (RCT).

qACE demonstrates increased GmNAC1b transcript cleavage in soybean roots over-expressing miR164

To obtain proof of concept for the method, we examined the abundance of cleavage remnants in miR164 over-expressing soybean roots. We isolated total RNA from vector control and miR164 overexpressing roots and examined mature miR164 levels by stem-loop qPCR. We observed an 6-fold increase in miR164 over-expressing roots compared to control roots as expected (Figure $2 \mathrm{a})^{31}$. We also examined the expression of GmNAC1b, a 5'-RACE-validated target of miR164 in soybean (Figure S1) and a close ortholog of AtNAC1 (Figure S2). We generated oligo-dT-primed cDNA and performed qPCR assays using primers designed across the miR164 binding site of GmNAC1b. Results from qPCR assays indicated that there was a 4.2-fold reduction in the levels of full-length GmNAC1b 

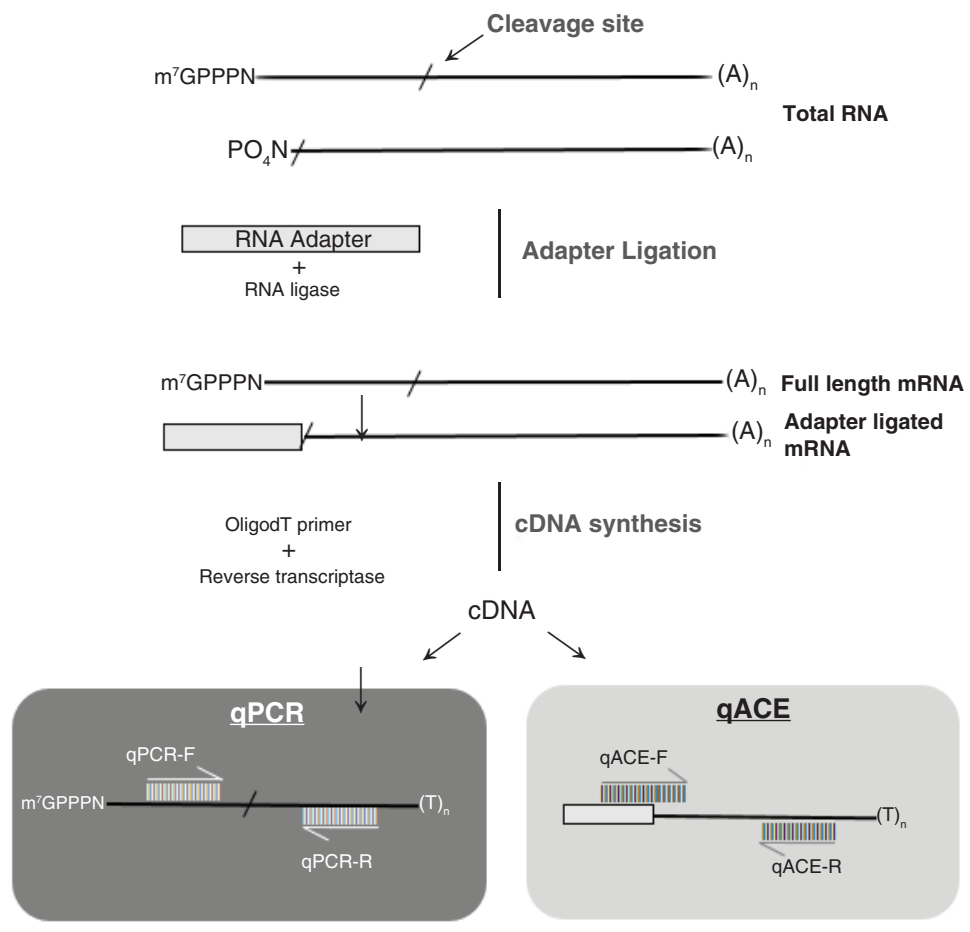

Figure 1. Quantitative Amplification of cDNA Ends (qACE). Total RNA containing full length transcripts with 7-methyl Guanosine/CAP and cleaved transcripts arising due to miRNA activity is used as starting material. An RNA oligo adapter of known sequence is ligated to the cleaved transcripts (with a 5'-Phosphate group) giving rise to adapter ligated mRNA. Oligo dT-primed cDNA is used to assay the levels of full length mRNA (qPCR) and cleaved transcripts ( $\mathrm{GACE}$ ). The $\mathrm{qPCR}$ forward and reverse primers (qPCR-F \& $\mathrm{qPCR}-\mathrm{R}$ ) were designed across the miRNA binding site whereas the qACE forward primer ( $\mathrm{AACE}-\mathrm{F}$ ) is designed complementary to adapter sequence but with six nucleotides at the 3'end specific to the sequence at 5'end of cleaved transcript, and a gene specific reverse primer (qACE-R).
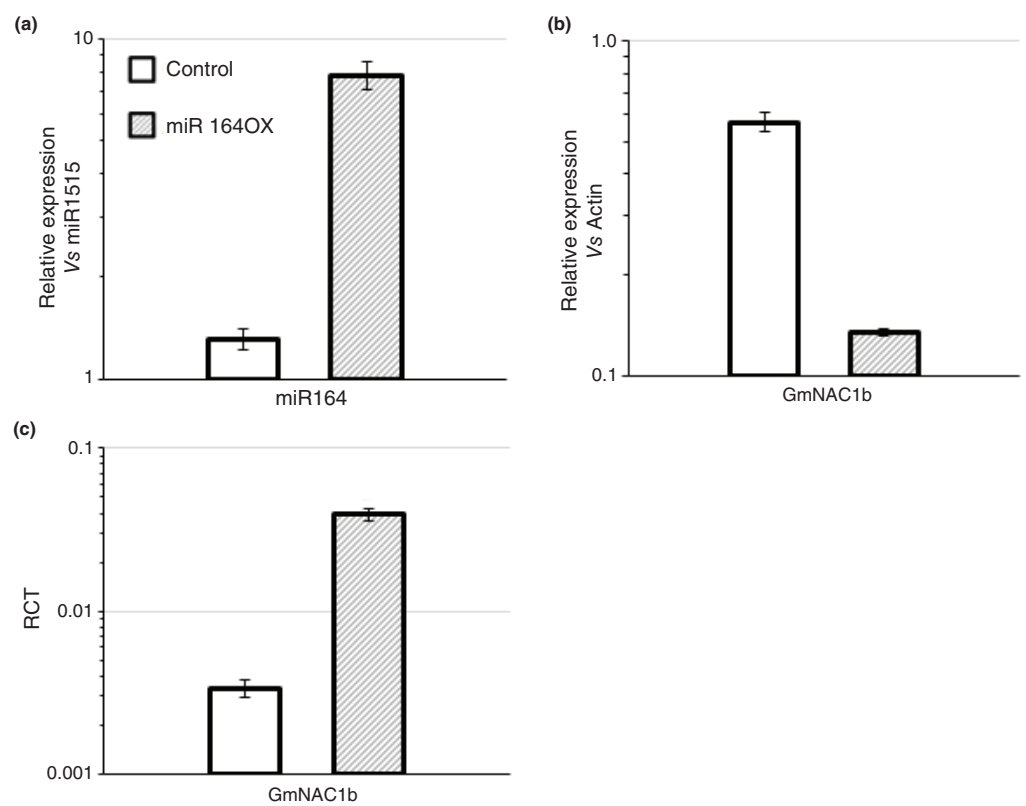

Figure 2. Increased cleavage of GmNAC1b transcripts by over expression of miR164 in soybean roots. (a) The relative expression level of miR164 (normalized to that of miR1515) in control soybean roots and those over-expressing miR164 (miR164ox) determined using stemloop qPCR. (b) The relative expression levels of full-length GmNAC1b (normalized to that of GmActin) in control and miR164ox roots assayed using qPCR. The data shown in (a) and (b) are average of three replicate assays and error bars indicate the range of possible values based on deviation between Ct values of replicate assays. (c) The Ratio of Cleaved Transcripts (RCT) over full-length transcripts of GmNAC1b in control and miR1640x roots assayed using qACE. The data shown are average of three replicate assays and error bars indicate the range of possible values based on deviation between Ct values of three replicate assays. 
transcripts in miR164 over-expressing roots compared to control roots (Figure $2 \mathrm{~b}$ ). These results indicated that indeed over-expression of miR164 resulted in a reduction in full-length transcripts of its target.

Next, we used qACE to detect and quantify target cleavage in these roots. We designed qACE primers for GmNAC1b as outlined in Figure 1. First we examined if the qACE primer pair does not amplify full-length molecules of GmNAC1b using the above cDNA from total RNA without any adapter ligation. qPCR assays detected no amplification (Figure S4a1) indicating that indeed qACE primers did not amplify/detect full-length GmNAC1b molecules. Next, we prepared adapter-ligated cDNA by ligating a known RNA adapter (see methods) to total RNA and reverse-transcribing these molecules using an oligo-dT primer. We used this cDNA to assay full length and cleaved molecules of GmNAC1b using the appropriate primer pairs (Figure 1) and calculated RCT values for each $\mathrm{NAC} 1 \mathrm{~b}$ in control and miR164 over-expressing roots. There was an 11.6-fold increase in the ratio of cleaved GmNAC1b transcripts in miR164 over-expressing roots compared to the control roots (Figure 2c) indicating that indeed miR164 over-expressing roots had increased cleavage of GmNAC1b. This experiment demonstrated that qACE could detect and provide a quantitative indicator of the levels of target cleavage.
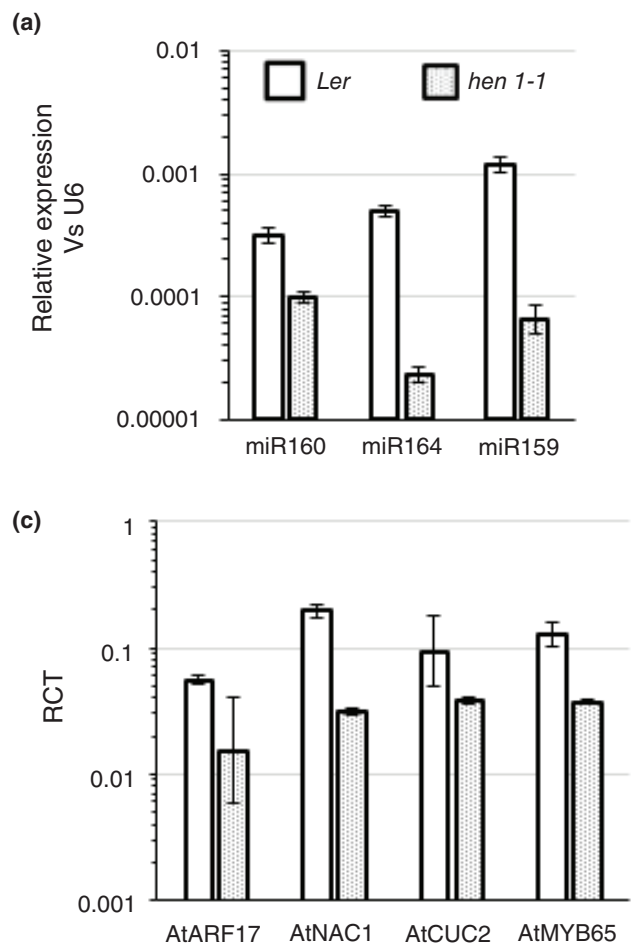

qACE demonstrates reduced target cleavage in miRNAdeficient Arabidopsis hen1-1 mutant plants

Next, we examined the levels of target cleavage in Arabidopsis wildtype (Ler) and miRNA-deficient hen 1-1 mutant plants. It was previously demonstrated that hen $1-1$ mutants accumulated less amounts of miRNAs and that there was an increase in the levels of miRNA targets in these plants ${ }^{25}$. We used stem-loop qPCR to determine the levels of three different conserved miRNAs: ath-miR160, athmiR164 and ath-miR159 in Arabidopsis Ler and hen1-1 plants ${ }^{27}$. As reported earlier, a clear reduction in the levels of mature miR160, miR164 and miR159 was observed in hen 1-1 plants in comparison to Ler (control) (Figure 3a). However, it should be noted that the levels of reduction were not uniform for all three miRNAs; fold change of $-3.2,-21$, and -18 respectively.

Next, we used qPCR and qACE respectively to determine the levels of full length and cleaved transcripts of selected targets of the above miRNAs. AtARF17 is an auxin response factor post-transcriptionally regulated by ath-miR $160^{32}$. As reported previously, we also observed an increase in the expression of AtARF17 in hen1-1 plants ( 1.4fold increase; Figure 3b). Similarly, AtNAC1 and AtCUC2, targets of ath-miR164 showed $\sim 3.5$ fold increase in gene expression levels in hen1-1 compared to Ler (Figure 3b). AtMYB65, known to be regulated by ath-miR159 had a 4.6-fold increase in transcript

(b)

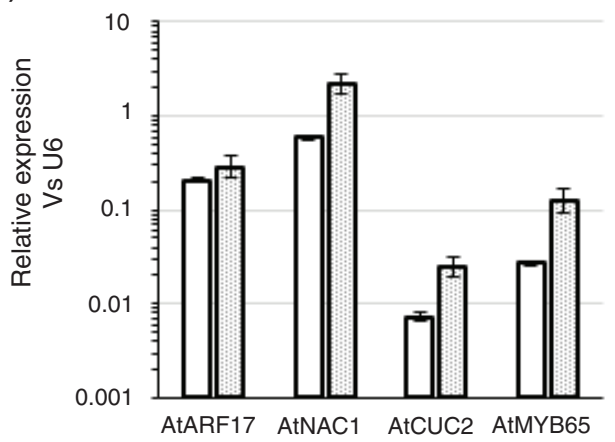

Figure 3. Reduced cleavage of target transcripts in miRNA-deficient arabidopsis hen1-1 mutants. (a) Expression of ath-miR160, ath-miR164 and ath-miR159 in wild-type Ler and hen1-1 tissues assayed by stem-loop qPCR. The expression levels of the miRNAs were normalized to U6. The data shown are average and error bars indicate the range of possible values based on deviation between Ct values of three replicate assays. (b) Levels of full-length target transcripts (AtARF17 target of miR160, AtNAC1 \& AtCUC2 target of miR164 and AtMYB65 target of miR159) in Ler and hen1-1 tissues analyzed using qPCR. Gene expression levels were normalized to U6 and further confirmed using two additional housekeeping genes, AtEF- $\alpha$ and AtGAPDH (data not shown). The data shown are average and error bars indicate the range of possible values based on deviation between Ct values of two replicate assays. (c) The Ratio of Cleaved Transcripts (RCT) over full-length transcripts of AtARF17, AtNAC1, AtCUC2, AtMYB65 in Ler and hen1-1 tissues assayed by qACE. Data shown are average and error bars indicate the range of possible values based on deviation between Ct values of two replicate assays. 
levels in henl-1 compared to Ler (Figure 3b). qACE assays indicated a significant reduction in the abundance of miRNA-directed cleavage products for all these target genes in hen1-1. For example, the levels of cleaved AtARF17 levels were lower in hen 1-1 plants resulting in a $\sim 3.5$-fold reduction in RCT (Figure 3c). Similarly, AtNAC1 had a 6.3-fold reduction in RCT in hen1-1 compared to Ler. AtCUC2 another target of miR164 had only a 2.5-fold decrease in RCT in hen 1-1 vs. Ler. Note that both AtNAC1 and AtCUC2 had a 3.5-fold increase in the levels of full-length transcripts (hen 1-1 vs. Ler) but the reduction in RCTs was very different. This data indicated that the extent of gene expression regulated by miR164 is perhaps different between these two targets. Possible reasons include differences in cleavage efficiency as well as differences in the extent of overlap in tissue domains where the miRNA and the targets are expressed ${ }^{33,34}$ qACE helped identify this difference where as simple comparison of full-length transcript levels by qPCR would not have identified it. Finally, AtMYB65 showed a $\sim 3.5$-fold reduction in RCT in henl-1 vs. Ler (Figure 3c). Evidence from these experiments clearly demonstrated the ability of qACE to provide a quantitative indicator of miRNA-directed cleavage of targets resulting from changes in cognate miRNA levels.

\section{Nodule specific expression of NAC1 transcription factors in} soybean

Having demonstrated the ability of qACE to detect and quantify cleavage of specific miRNA targets, we used the technique to examine the role of miRNAs in governing nodule-specific/enriched

(a)

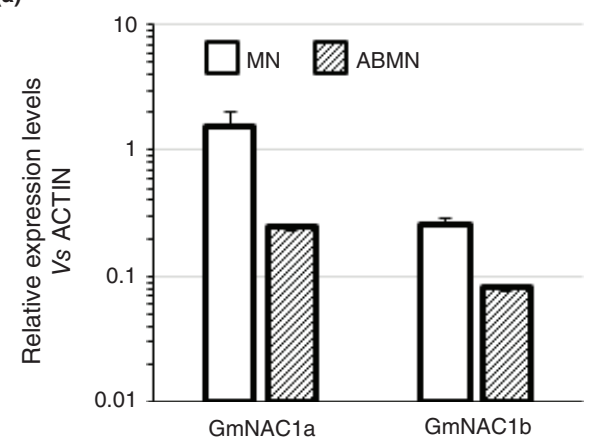

(c)

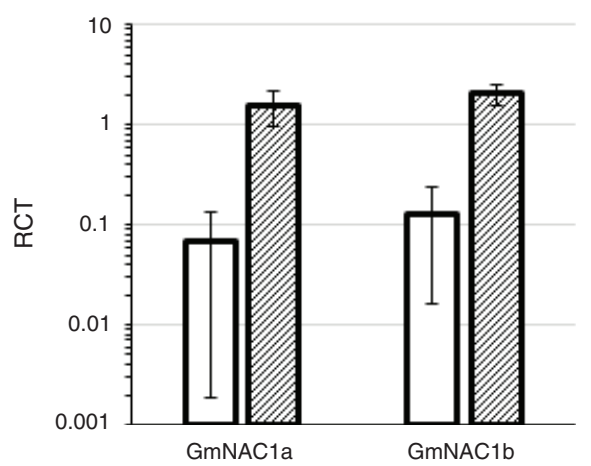

gene expression in soybean. We compiled a total of 326 miRNA genes classified in to 134 families from soybean and predicted a total of 596 genes targeted by these miRNAs in soybean ${ }^{35}$. Among these, a set of miRNA-target pairs had inverse expression pattern between mature symbiotic nodules $(\mathrm{MN})$ and adjacent root tissues (ABMN; data not shown). We identified two NAC transcription factors, GmNAC1a and GmNAC1b (5'-RACE validated targets of miR164) that were expressed in a nodule-enriched manner. While GmNAC1a had 6.3-fold higher expression in $\mathrm{MN}$ vs. ABMN tissues, GmNAC1b had a 3.2-fold higher expression (Figure 4a). Interestingly, miR164 had a nodule-excluded expression pattern i.e. 40-fold lower expression in MN vs ABMN (Figure 4b).

Based on such inverse expression of these miRNA-target pairs we hypothesized that nodule-specific expression of these target genes might be at least in part regulated by nodule-excluded expression of miR164. In other words, miR164 might actively cleave these target genes in adjacent root tissues to restrict their expression to the nodules. Such a mechanism combined with transcriptional regulation can be used to generate expression gradients as observed between miR166 and its HD-ZIP III proteins during xylem development $^{36}$. However, mere inverse expression of miRNAs and their targets is not conclusive evidence for our hypothesis. If indeed, these target genes were preferentially cleaved in ABMN tissues to ensure $\mathrm{MN}$-specific expression, we would expect to observe a larger proportion of cleaved transcripts in ABMN tissues vs. MN tissues.

(b)

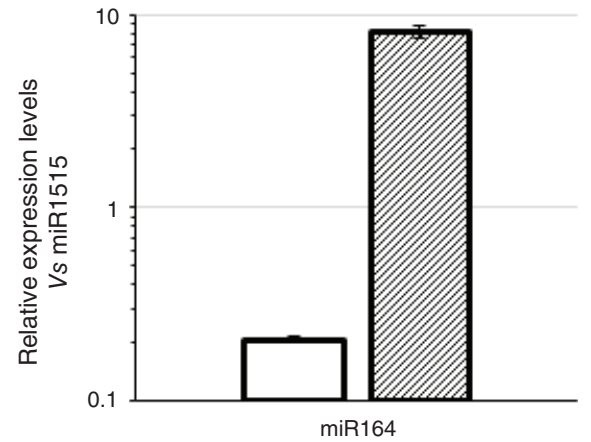

Figure 4. Nodule-enriched gene expression directed by miRNA activity in soybean. (a) Levels of full-length GmNAC1a \& b transcript levels in mature nodules (MN) and adjacent root tissues (ABMN) assayed by qPCR and expression levels were normalized to GmActin. Data shown are average and error bars indicate the range of possible values based on deviation between $\mathrm{Ct}$ values of two replicate assays. (b) Level of gma-miR164 in MN and ABMN tissues assayed by stem-loop qPCR. miRNA expression levels were normalized to that of miR1515. Data shown are average and error bars indicate the range of possible values based on deviation between Ct values of three replicate assays. (c) The Ratio of Cleaved Transcripts (RCT) over full-length transcripts of GmNAC1a \& b assayed by qACE. Data shown are average from two biological replicates and error bars indicate \pm SD. 
We used qACE to determine the cleavage levels of GmNAC1a and GmNAC1b in ABMN and MN tissues and calculated RCT values. It is worth noting that these targets share the same cleavage signature in degradome/PARE analyses (Table S1). We designed gene specific reverse primers that distinguished these genes (Table S2 and Figure S3a \& b). Both GmNAC1a and GmNAC1b had increased cleavage in $\mathrm{ABMN}$ tissues compared to $\mathrm{MN}$ tissues. Interestingly, consistent with the higher enrichment of GmNAC1a in MN tissues, this gene had a higher cleavage in ABMN tissues ( 23.5-fold higher than $\mathrm{MN}$ tissues). GmNAC1b also had higher cleavage in ABMN tissues ( 15.8-fold higher than MN tissues; Figure 4c). Increased cleavage of GmNAC1a in ABMN compared to GmNAC1b was consistent with increased enrichment of full length GmNAC1a transcripts in $\mathrm{MN}$ compared to that of GmNAC1b. qACE assays strongly support the hypothesis that increased cleavage of targets in ABMN tissues by miR164 contributes at least in part to determine their nodule-enriched expression.

In summary, we have demonstrated that qACE can detect and quantify miRNA-directed cleavage of specific target genes using miRNA over-expression and miRNA-deficient tissues. We successfully used the technique to identify differential cleavage of specific target genes between nodule and adjacent root tissues revealing an additional miRNA-directed mechanism that results in nodule-specific/ enriched gene expression.

Dataset 1. Raw data qACE to assay miRNA-directed target cleavage

http://dx.doi.org/10.5256/f1000research.5266.d36383

Dataset 1.

Raw Ct values corresponding to Figure 2 .

Dataset 2.

Raw Ct values corresponding to Figure 3 .

Dataset 3.

Raw Ct values corresponding to Figure 4 .

\section{Discussion}

qACE provides a quantitative indicator of miRNA-directed cleavage of specific target genes by assaying the levels of cleavage remnants. A number of studies have shown reduced levels of target transcripts as an indirect evidence of miRNA-directed cleavage ${ }^{36,37}$. Northern hybridization has also been used to estimate miRNA-directed cleavage. For example, a putative cleavage product of NAC1 resulting from miR164 activity was detected using a 3'-specific probe in Arabidopsis $^{33}$. More recently, degradome/PARE analysis has enabled quantification of global miRNA cleavage ${ }^{17,18}$. However, this method cannot distinguish target transcripts that share the same cleavage signature (see Introduction). qACE, an enhancement to the semi-quantitative method developed by Schwab et al. $2005^{14}$, enables quantification of miRNA-directed cleavage of a smaller set of target genes and also can differentiate closely related genes. During the preparation of this manuscript a near identical method was used by Li et al. $(2014)^{38}$ to distinguish efficiencies of miR159-directed cleavage of different MYB33 targets with specific mismatches. This study validated the usefulness of the qACE method. We have performed proof of concept and control experiments (e.g. demonstrating lack of amplification using qACE primers in non-adapter ligated cDNA preparations) to demonstrate the method's utility.
We have demonstrated this using GmNAC1a and GmNAC1b which share a similar cleavage signature (Table S1). Our results show that using qPCR (to assay reduction in full-length transcripts) and qACE (to assay the levels of cleaved transcripts) on the same cDNA preparation, one can estimate specific levels of cleavage for each target gene. For example, we demonstrate that both NAC1 and CUC2 had similar levels of increase in hen 1-1, but different levels of reduction in miR164-directed cleavage.

It should be noted that qACE relies on prior knowledge about the validity of the cleavage site e.g. obtained through 5'-RACE or degradome/PARE analyses. It cannot be used to validate a predicted cleavage site. In addition, one has to assume that the stability of cleavage products are identical among multiple target genes that are compared. However, such an assumption has to be made even for alternate methods such as degradome/PARE analysis. A potential limitation of qACE is the level of target gene expression and thus the detectable level of cleavage products. Among the different genes we tested, RCTs ranged from 0.0033 (GmNAC1b Figure 2c) to 0.2 (AtNAC1; Figure 3c). As one can imagine, for very poorly expressed genes with a low levels of miRNA cleavage, it can be technically challenging to reliably detect cleavage products. We used linearity and efficiency assays to determine valid range of $\mathrm{Ct}$ values that are reliable for each gene of interest (See below). Alternate solutions to this deficiency include the use of xrn 4 mutants as done previously ${ }^{18}$ or the use of linear pre-amplification of the adapter-ligated RNA molecules by incorporating a T7 promoter in the adapter. However, this will amplify only cleaved products and not full-length transcripts. In addition, specific miRNAs also induce generation of secondary sRNAs from the cleaved product making them unavailable for quantification. Another limitation of qACE is its inability to distinguish cleavage products with closely spaced cleavage sites. For example, G. max has twenty miR166 genes that are predicted to target all twelve GmHD-ZIP III genes. We have identified two major cleavage products from several of these genes where the position of cleavage site differs by two nucleotides. Based on the known miR166 variants in soybean, we hypothesized that these two cleavage products arose from the activities of miR166a and miR166h respectively (Figure 5). We attempted to distinguish these cleavage products by qACE. Unfortunately qACE failed to differentiate the cleaved molecules arising due to gma-miR166h owing to loop formation in template which enables amplification of the qACE primer pairs designed to detect cleavage levels arising due to miR166a. Despite these minor limitations, we have demonstrated that qACE is a very useful method that can provide a quantitative indicator of the cleavage levels of specific miRNA target genes.

qACE being a qPCR-based method, specificity and linearity of primers used are key factors to be considered ${ }^{39}$. The first level of specificity is to ensure that the qACE forward primer does not amplify full-length cDNA molecules or bind non-specifically to other adapter-ligated molecules. We achieved this by careful design such that this primer corresponds to the adapter-cleavage product junction with 6 nucleotides at the 3 'end of the primer corresponding to the nucleotides downstream of the cleavage site in the target gene. A shorter design (a 4 nt sequence for example), might result in non-specific binding to non-specific cleavage products due to the increased probability of binding sites (data not shown). This can potentially be overcome with a gene-specific reverse primer (See 

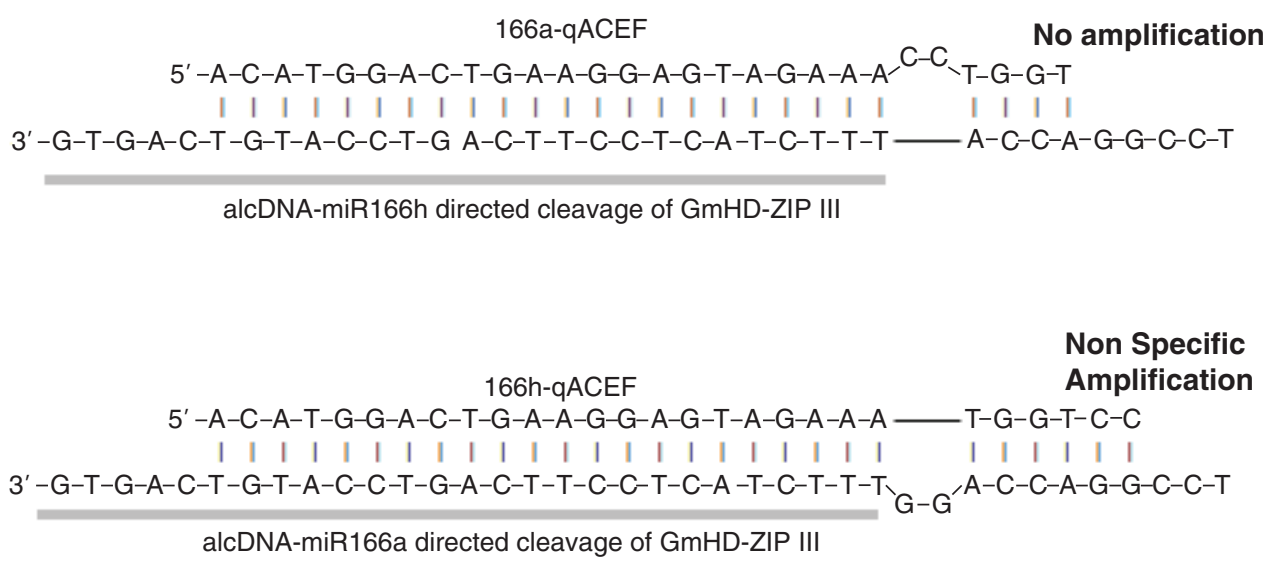

Figure 5. Cleavage products with closely spaced cleavage sites and difficulty in detection using qACE. The images depict binding of the qACE forward primer (qACE-F) to cleavage products resulting from miR166h and miR166a guided cleavage of GmHD-ZIP III transcripts. The primer-template combination in the top panel resulted in no amplification underscoring the specificity of the primer. However, the primertemplate combination shown in the bottom panel resulted in non-specific amplification. We hypothesize that the 6nt binding stretch at the 3'end was the reason for such non-specific amplification. The oligo adapter ligated to the cleaved end is indicated in bold letters and as grey bar.

below). On the other hand, longer than 6 nt design had a higher thermodynamic stability making it possible to bind to full-length cDNA molecules (depending on the GC content; data not shown). The second level of specificity is distinguishing target genes with identical miRNA cleavage signatures (and therefore having identical qACE forward primers). This is again achieved by carefully designing gene-specific reverse primers. For linearity assays for qACE primers, one has to use adapter-ligated cDNA. Due to the lower abundance of cleavage products, we made cDNA preparations from $5-7 \mu \mathrm{g}$ of DNase treated total RNA. To efficiently utilize these cDNA preparations for qACE assays, we used PCR amplified cDNA for linearity assays. We amplified a small amount of adapterligated cDNA using 5'adapter as forward primer and 3' PolydT adapter as reverse primer in a 25 cycle PCR. We reasoned that dilutions of this PCR product can be used to check the linearity of the qACE primer pairs, but cannot be used for qACE assays (due to non-linear amplification). This enabled the use of adapter-ligated cDNA primarily for qACE assays and increased the overall efficiency of the method in terms of amount of RNA requirement.

\section{Data availability}

F1000Research: Dataset 1. Raw data qACE to assay miRNAdirected target cleavage, 10.5256/f1000research.5266.d $36383^{40}$

\section{Author contributions}

SS conceived the study, guided data analysis, and wrote the manuscript. SD, SA and MT performed the experiments. SD and SA analyzed the data and co-wrote the manuscript.

\section{Competing interests}

No competing interests were disclosed.

\section{Grant information}

Research in the authors' laboratory is supported by funds (awarded to S.S) from USDA-AFRI (2010-65116-20514), NSF-PGRP (IOS1350189), South Dakota Soybean Research and Promotion Council and South Dakota State University and Agricultural Experiment station.

The funders had no role in study design, data collection and analysis, decision to publish, or preparation of the manuscript.

\section{Acknowledgements}

The use of equipment at the SDSU-Functional Genomics Core Facility supported in part by NSF/EPSCoR Grant No. 0091948, the State of South Dakota is acknowledged.

\section{Supplementary information}

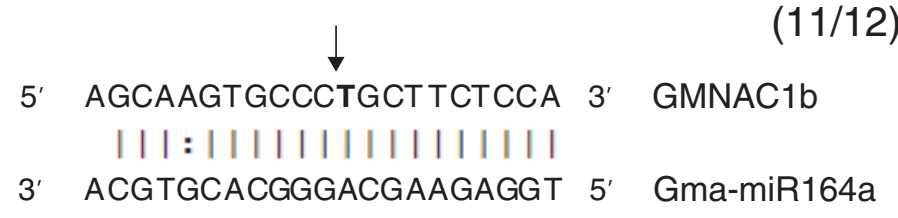

Figure S1. Validation of gma-miR164a guided cleavage of GmNAC1b using RLM 5'-RACE. The arrow indicates the cleavage site in the miR164a binding site of GmNAC1b. The numbers within parenthesis indicate the frequency of miRNA cleaved product of the total number of sequences analyzed. 


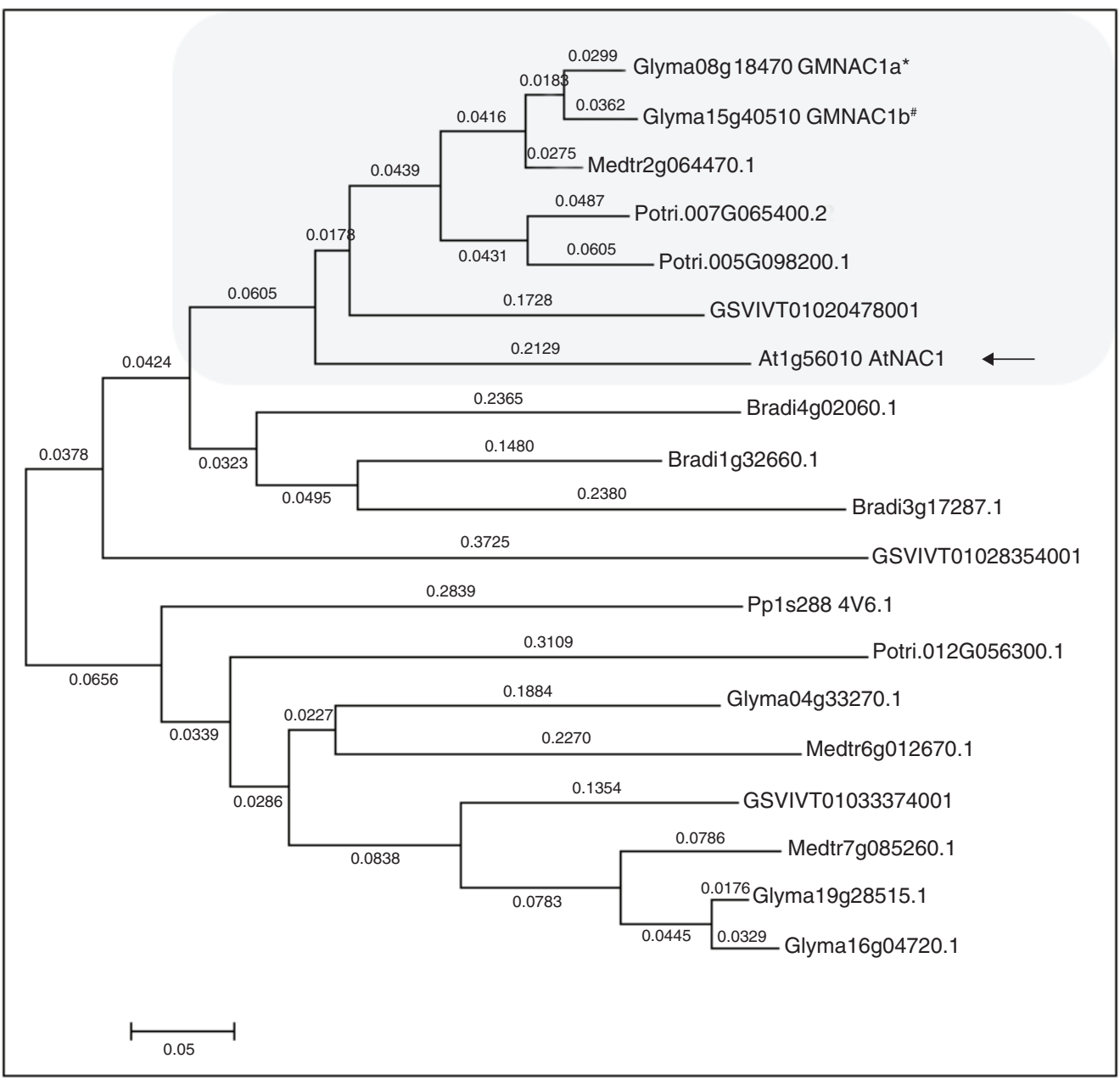

Figure S2. Phylogenetic tree of NAC1 transcription factor peptide sequence of AtNAC1 (At1g56010), NAC1 orthologs in Glycine max, Medicago truncatula, Poplar trichocharpa, Vitis vinifera, Brachypodium distachyon were identified using BLASTP tool in Phytozome (www.phytozome.net). The amino acid sequences were aligned using global alignment in MEGA 5. The aligned sequences were used for constructing a phylogenetic tree using the rooted neighborhood joining method. The numbers in the branches indicate the distance and arrows shows the GmNAC1b presence in AtNAC1 clade.
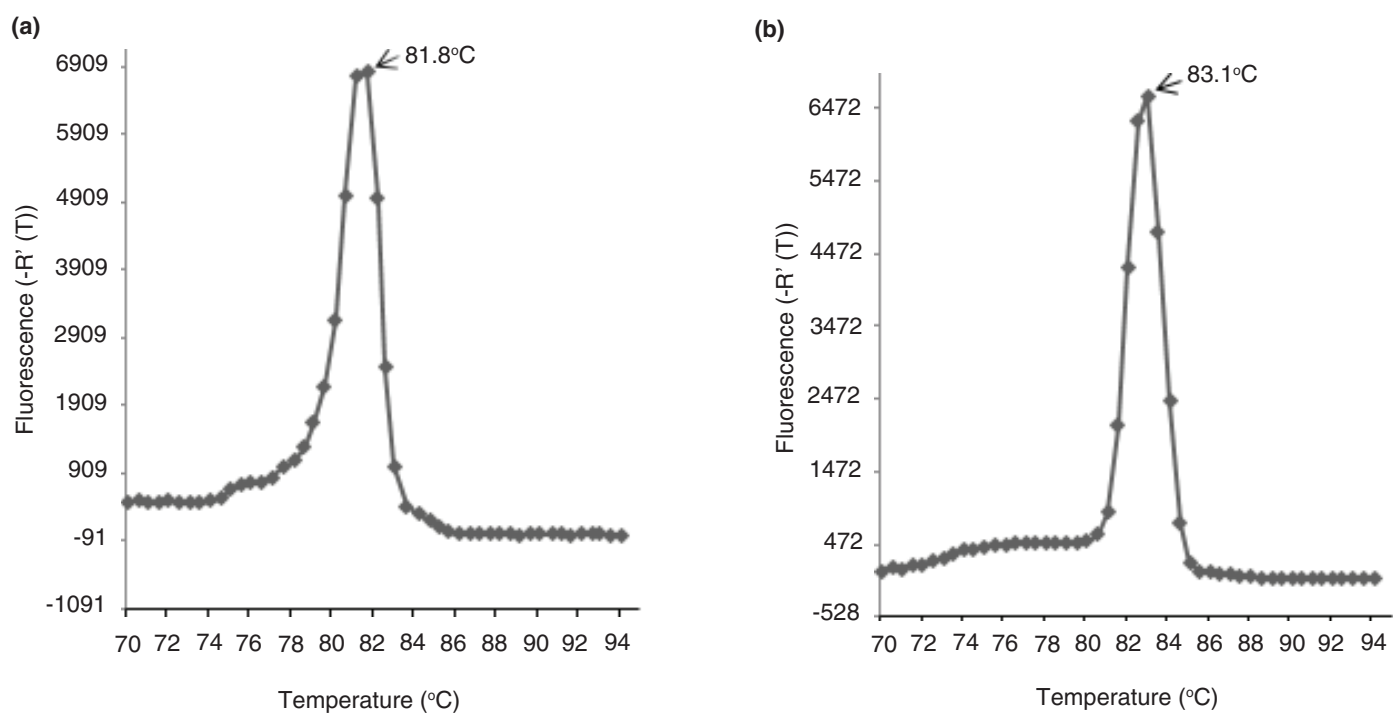

Figure S3. Dissociation curves of qACE amplicons (a) GmNAC1a and (b) GmNAC1b. The melting temperatures (Tm) are different for GmNAC1a and GmNAC1b underscoring the specificity of the gene specific reverse primer although the qACE-F primer is common for both. The data is the average of two replicate assays. 
(a1)

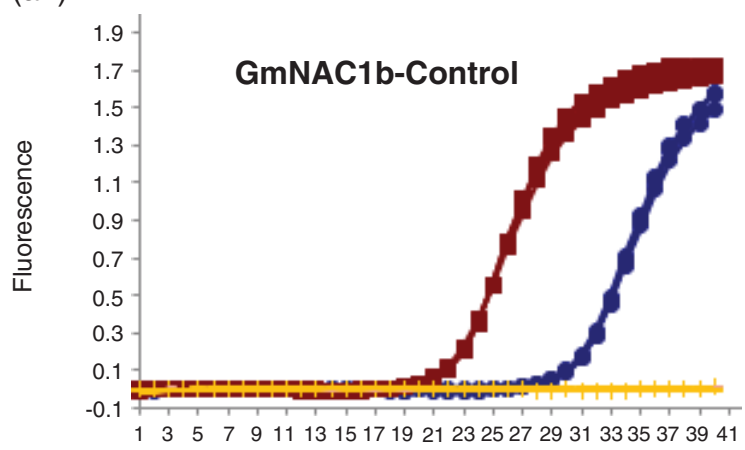

(a2)

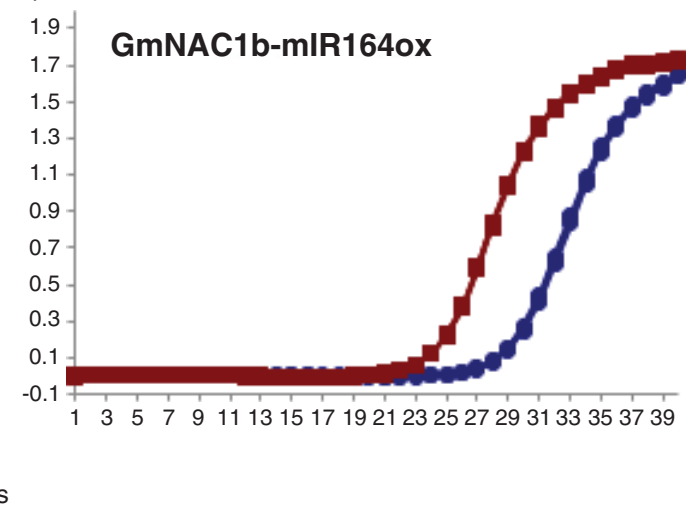

Figure S4a. Amplification plots of GmNAC1b in (a1) control and (a2) miR164ox (miR164 over expression) amplification plots showing linear amplification of full length (red squares) and cleaved cDNA (blue circles) by GmNAC1b qPCR-F \& R and qACE-F \& R primers respectively determined by SYBR fluorescence. (a1) Amplification plot showing no amplification of full length cDNA by GmNAC1b qACE-F \& R primers determined by SYBR fluorescence (yellow lines). The data shown are normalized fluorescence from three replicate assays.

(b1)
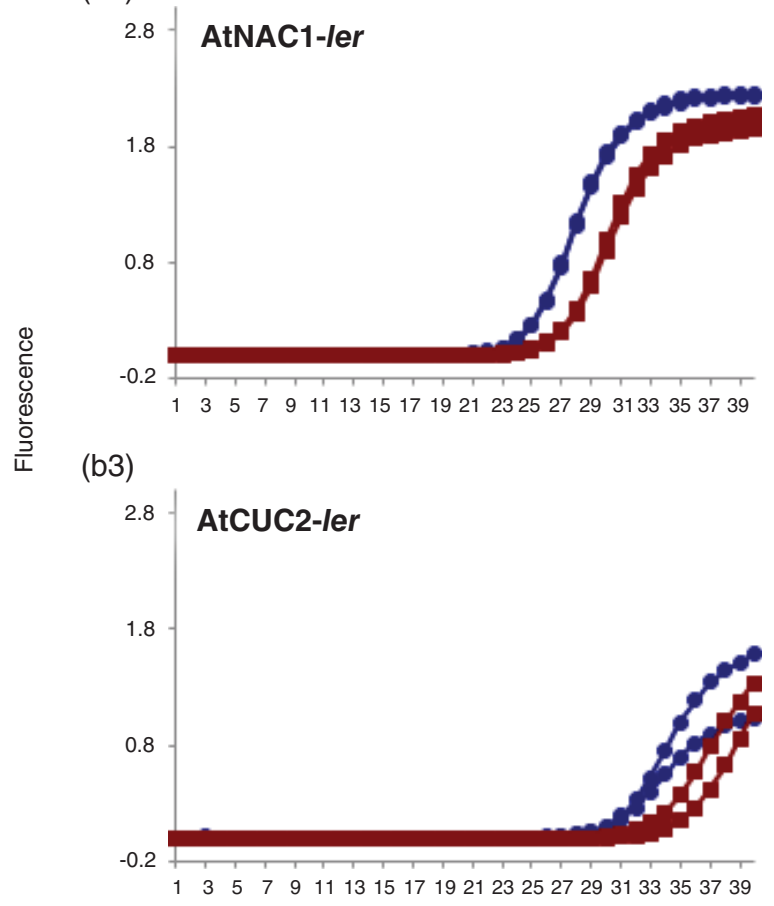

(b2)

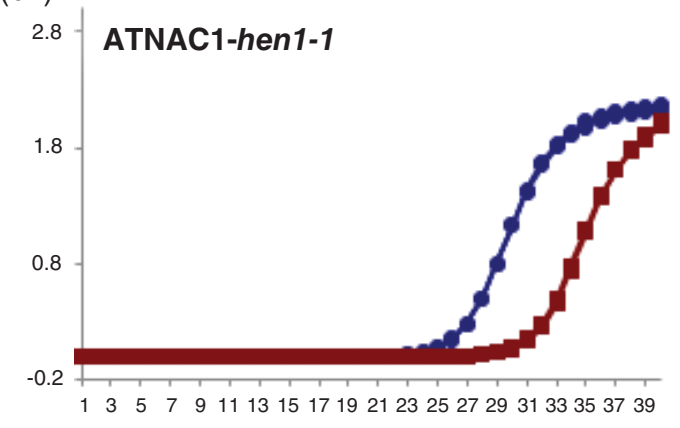

(b4)

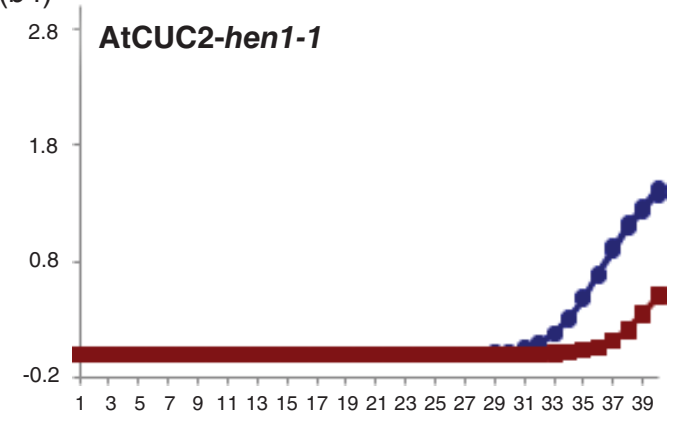

Cycles

Figure S4b. Amplification plots of AtNAC1 \& AtCUC2 in (b1 \& b3) Ler and (b2 \& b4) hen 1-1 Arabidopsis mutant. Amplification plot showing linear amplification of full length (blue circles) and cleaved CDNA (red squares) by qPCR-F \& R and qACE-F \& R primers respectively for AtNAC1 (b1 \& b2), AtCUC2 (b3 \& b4) determined by SYBR fluorescence. The data shown are normalized fluorescence from two replicate assays. 
(c1)

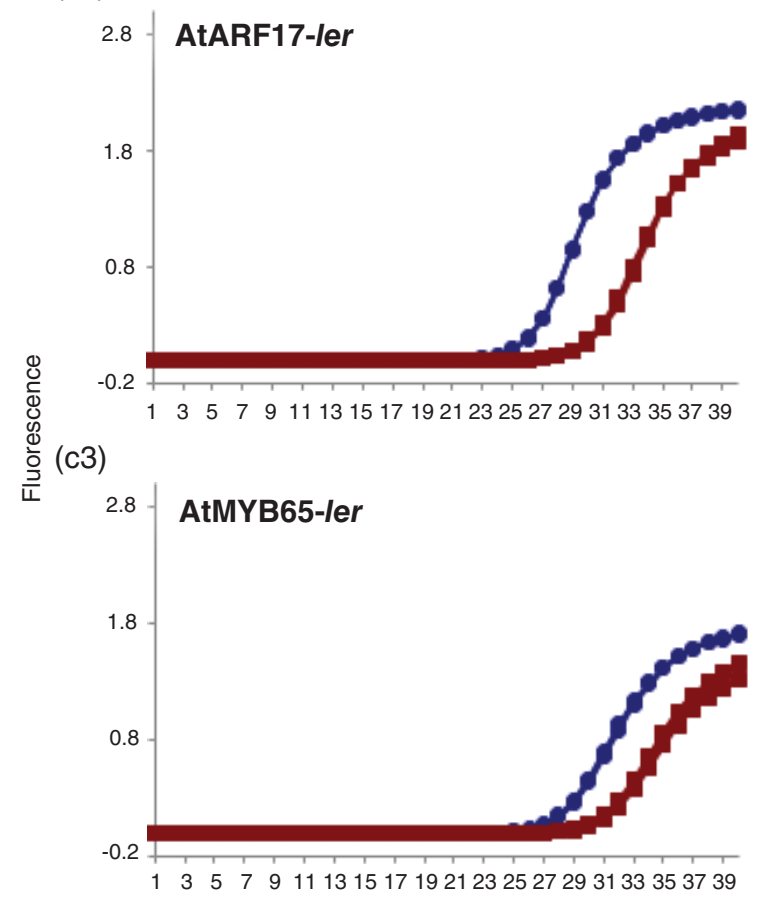

(c2)

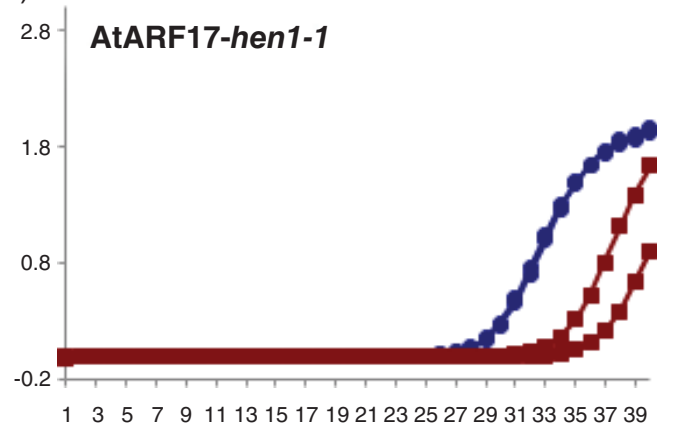

(c4)

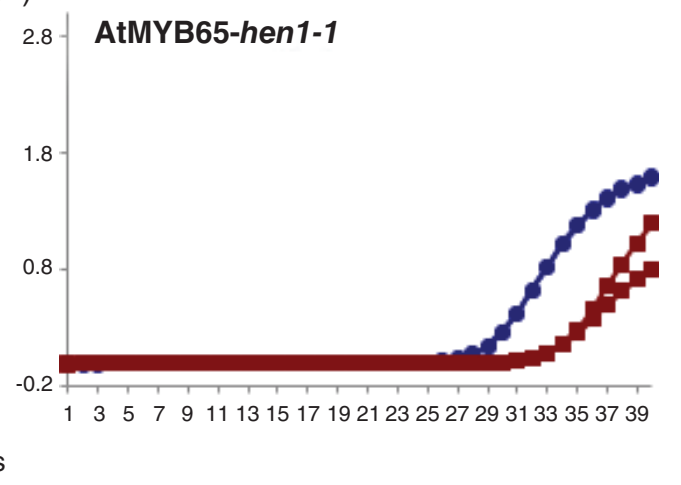

Figure S4c. Amplification plots of AtARF17 \& AtMYB65 in (c1 \& c3) Ler and (c2 \& c4) hen1-1 Arabidopsis mutant. Amplification plot showing linear amplification of full length (blue circles) and cleaved CDNA (red squares) by qPCR-F \& $R$ and $q A C E-F \& R$ primers respectively for AtARF17 (c1 \& c2), AtMYB65 (c3 \& c4) determined by SYBR fluorescence. The data shown are normalized fluorescence from two replicate assays.

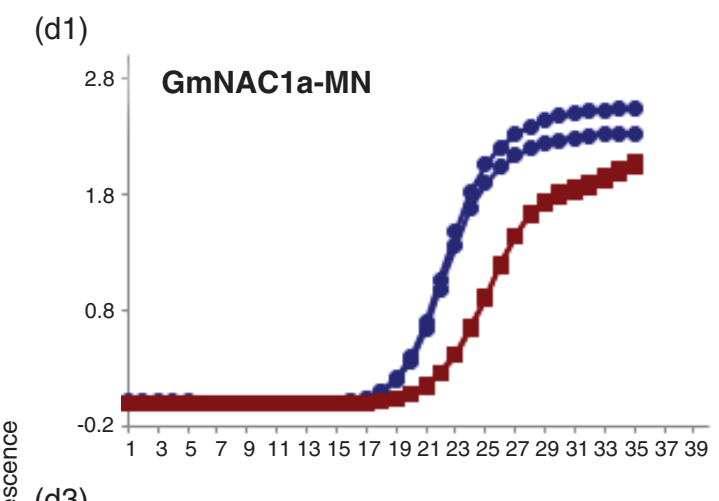

$(\mathrm{d} 3)$

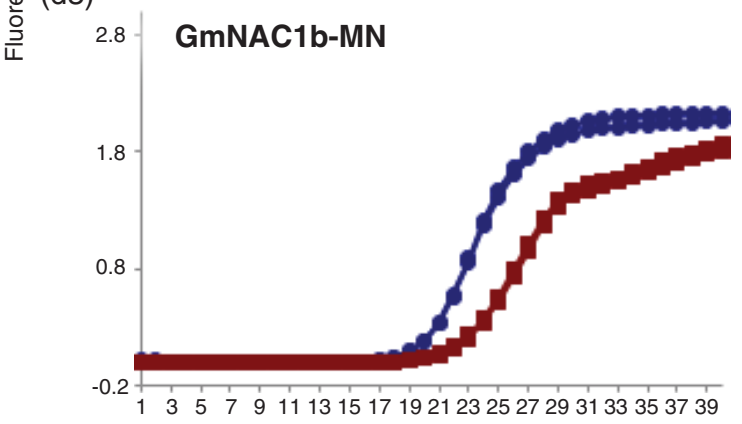

(d2)

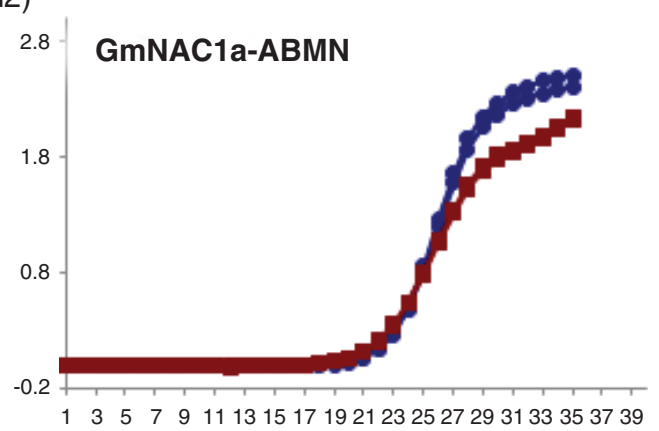

(d4)

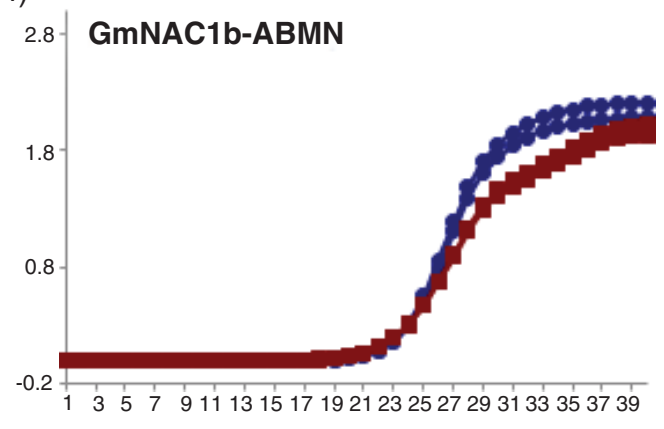

Cycles

Figure S4d. Amplification plots of GmNAC1a \& b in (d1 \& d3) MN (d2 \& d4) ABMN tissues of soybean. Amplification plot showing linear amplification of full length (blue circles) and cleaved cDNA (red squares) by qPCR-F \& R and qACE-F \& R primers respectively for GmNAC1a (d1 \& d2), GmNAC1b (d3 \& d4) determined by SYBR fluorescence. The data shown are normalized fluorescence from two replicate assays. 
Table S1. Examples of miRNA targets with identical cleavage signatures in degradome/PARE libraries.

\begin{tabular}{|c|c|c|c|}
\hline Species & $\begin{array}{l}\text { miRNA family } \\
\text { analyzed }\end{array}$ & $\begin{array}{l}\text { Targets sharing identical cleavage } \\
\text { signature with at least one other } \\
\text { target of its cognate miRNA }\end{array}$ & $\begin{array}{l}\text { Percentage of targets with } \\
\text { shared cleavage signatures } \\
\text { with at least one other target } \\
\text { of the cognate miRNA }\end{array}$ \\
\hline \multirow[t]{27}{*}{ Soybean } & \multirow[t]{5}{*}{ miR160 } & Glyma10g35480.1 $1^{a}$ & \multirow[t]{5}{*}{$41.7 \%(5 / 12)$} \\
\hline & & Glyma11g20490.1 & \\
\hline & & Glyma12g08110.19a & \\
\hline & & Glyma13g20370.1 & \\
\hline & & Glyma10g06080.1 & \\
\hline & \multirow[t]{6}{*}{$\operatorname{miR} 164$} & Glyma04g33270.1 $1^{a}$ & \multirow[t]{6}{*}{$85.7 \%(6 / 7)$} \\
\hline & & Glyma05g00930.1 $1^{a}$ & \\
\hline & & Glyma06g21020.1 $1^{a}$ & \\
\hline & & Glyma17g10970.19a & \\
\hline & & Glyma08g18470.1 & \\
\hline & & Glyma15g40510.1 & \\
\hline & \multirow[t]{12}{*}{ miR166 } & Glyma04g09000. $1^{\mathrm{b}}$ & \multirow[t]{12}{*}{$100 \%(12 / 12)$} \\
\hline & & Glyma05g30000.1 $1^{a}$ & \\
\hline & & Glyma06g09100.1 & \\
\hline & & Glyma07g01940.1 b & \\
\hline & & Glyma07g01950.1 $1^{b}$ & \\
\hline & & Glyma08g13110.1 & \\
\hline & & Glyma08g21610.1 & \\
\hline & & Glyma08g21620.1 & \\
\hline & & Glyma09g02750.1 $1^{a}$ & \\
\hline & & Glyma11g20520.1c & \\
\hline & & Glyma12g08080.1 $1^{c}$ & \\
\hline & & Glyma15g13640.1 & \\
\hline & \multirow[t]{2}{*}{ miR169 } & Glyma09g07960.1 $1^{a}$ & \multirow[t]{2}{*}{$40 \%(2 / 5)$} \\
\hline & & Glyma15g18970.1 & \\
\hline & \multirow[t]{2}{*}{ miR159 } & Glyma04g15150.19 & \multirow[t]{2}{*}{$40 \%(2 / 5)$} \\
\hline & & Glyma06g47000.1 $1^{a}$ & \\
\hline \multirow[t]{4}{*}{ Arabidopsis } & \multirow[t]{2}{*}{ miR319a } & AT2G45950.1 $1^{\mathrm{a}}$ & \multirow[t]{2}{*}{$16.7 \%(2 / 12)$} \\
\hline & & AT3G61415.1 $1^{\mathrm{a}}$ & \\
\hline & \multirow[t]{2}{*}{ miR172d } & AT3G23810.1 $1^{\mathrm{a}}$ & \multirow[t]{2}{*}{$25 \%(2 / 8)$} \\
\hline & & AT4G13940.1 $1^{\mathrm{a}}$ & \\
\hline
\end{tabular}

The data was obtained for Arabidopsis (German et al., 2009) \& Soybean (Shamimuzzaman and Vodkin 2012). Targets of a particular miRNA family with identical cleavage signatures are denoted by the same letter label (a,b, or c). 
Table S2. Sequences of PCR primers used in this study.

\begin{tabular}{|c|c|c|}
\hline Gene & Forward primer & Reverse primer \\
\hline \multicolumn{3}{|l|}{ Arabidopsis qPCR Primers } \\
\hline ATGAPDH(At1g13440) & ttggtgacaacaggtcaagca & aaacttgtcgctcaatgcaatc \\
\hline AtEF1 $\alpha(A t 5 g 60390)$ & tgagcacgctcttcttgctttca & ggtggtggcatccatcttgttaca \\
\hline Universal U6 & ggaacgatacagagaagattagca & gtgcagggtccgaggttttggaccatttctcgat \\
\hline ATNAC1(At1g56010) & gaccaagaaccctcttcttatctcag & gactgagttggttaggttcgagt \\
\hline ATCUC2(At5g53950) & cctacgacagccgtagcacc & tgagttaacgtctaagcccaaggc \\
\hline ATARF17(At1g77850) & gatccaagtccttctatgttctcgta & cccaaatcaggaagcggactt \\
\hline ATMYB65(At3g11440) & acgtatggcatgcatcctacttc & Gtggaggtgacggagtcgt \\
\hline \multicolumn{3}{|l|}{ Arabidopsis qACE primers } \\
\hline AtNAC1 & acatggactgaaggagtagaaatgcttc & gactgagttggttaggttcgagt \\
\hline AtCUC2 & acatggactgaaggagtagaaatgtttc & tgagttaacgtctaagcccaaggc \\
\hline AtARF17 & acatggactgaaggagtagaaagagcca & cccaaatcaggaagcggactt \\
\hline AtMYB65 & acatggactgaaggagtagaaatcattc & Gtggaggtgacggagtcgt \\
\hline \multicolumn{3}{|l|}{ Soybean qPCR primers } \\
\hline GmACTIN(Glyma02g10170) & ccggtcgtgacctcactgatttcttg & catcaggcaactcgtagctcttctcg \\
\hline GmNAC1a(Glyma08g18470) & cgggatcttcaactcttcctgcg & gagggaacttaggctccatagtggt \\
\hline GmNAC1b(Glyma15g40510) & ctgctatgaggacacaggatcttcat & Aaatttggtgctcctccatatgcat \\
\hline \multicolumn{3}{|l|}{ Soybean qACE primers } \\
\hline GmNAC1a(Glyma08g18470) & \multirow[t]{2}{*}{ acatggactgaaggagtagaaatgcttc } & gagggaacttaggctccatagtggt \\
\hline GmNAC1b(Glyma15g40510) & & aaatttggtgctcctccatatgcat \\
\hline GmHD-ZIPIII-166a & acatggactgaaggagtagaaacctggt & \\
\hline GmHD-ZIPIII-166h & acatggactgaaggagtagaaatggtcc & \\
\hline \multicolumn{3}{|l|}{ miRNA cDNA synthesis primer } \\
\hline AtmiR159a & & gtcgtatccagtgcagggtccgaggtattcgcactggatacgactagagc \\
\hline AtmiR159b & & gtcgtatccagtgcagggtccgaggtattcgcactggatacgacaagagc \\
\hline AtmiR159c & & gtcgtatccagtgcagggtccgaggtattcgcactggatacgacaggagc \\
\hline $\operatorname{miR} 164$ & & gtcgtatccagtgcagggtccgaggtattcgcactggatacgactgcacg \\
\hline GmmIR1515 & & gtcgtatccagtgcagggtccgaggtattcgcactggatacgaccagatc \\
\hline $\operatorname{miR} 160$ & & Gtcgtatccagtgcagggtccgaggtattcgcactggatacgactggcat \\
\hline \multicolumn{3}{|l|}{ miRNA qPCR primer } \\
\hline qPCR-atmiR159-F & tcgcttttggattgaaggga & \multirow{5}{*}{ Gtgcagggtccgaggt } \\
\hline qPCR-MIR164-F & tggagaagcagggcacgtgca & \\
\hline qPCR-miR1515-F & tcgcttcattttgcgtgcaat & \\
\hline qPCR-miR160-F & tgcctggetccctgtatgcca & \\
\hline qPCR-universal miRNA-R & & \\
\hline
\end{tabular}


1. Reinhart BJ, Weinstein EG, Rhoades MW, et al:: MicroRNAs in plants. Genes Dev. 2002; 16(13): 1616-26.

PubMed Abstract | Publisher Full Text | Free Full Text

2. Jover-Gil S, Candela H, Ponce MR: Plant microRNAs and development. Int J Dev Biol. 2005; 49(5-6): 733-44.

PubMed Abstract | Publisher Full Tex

3. Jones-Rhoades MW, Bartel DP, Bartel B: MicroRNAs and their regulatory roles in plants. Annu Rev Plant Biol. 2006; 57: 19-53.

PubMed Abstract | Publisher Full Text

4. Chen X: Small RNAs and their roles in plant development. Annu Rev Cell Dev Biol. 2009; 25: 21-44.

PubMed Abstract | Publisher Full Text

5. Emery JF, Floyd SK, Alvarez J, et al.: Radial patterning of Arabidopsis shoots by class III HD-ZIP and KANADI genes. Curr Biol. 2003; 13(20): 1768-74. PubMed Abstract | Publisher Full Text

6. Prigge MJ, Otsuga D, Alonso JM, et al:: Class III homeodomain-leucine zipper gene family members have overlapping, antagonistic, and distinct roles in Arabidopsis development. Plant Cell. 2005; 17(1): 61-76. PubMed Abstract | Publisher Full Text | Free Full Text

7. Juarez MT, Kui JS, Thomas J, et al.: microRNA-mediated repression of rolled leaf1 specifies maize leaf polarity. Nature. 2004; 428(6978): 84-8.

PubMed Abstract | Publisher Full Tex

8. Mallory AC, Reinhart BJ, Jones-Rhoades MW, et al:: MicroRNA control of PHABULOSA in leaf development: importance of pairing to the microRNA 5 region. EMBO J. 2004; 23(16): 3356-64.

PubMed Abstract | Publisher Full Text | Free Full Text

9. Wong CE, Zhao YT, Wang XJ, et al:: MicroRNAs in the shoot apical meristem of soybean. J Exp Bot. 2011. 62(8): 2495-506. PubMed Abstract | Publisher Full Text

10. Combier JP, Frugier F, de Billy F, et al:: MtHAP2-1 is a key transcriptional regulator of symbiotic nodule development regulated by microRNA169 in Medicago truncatula. Gene Dev. 2006; 20(22): 3084-8. PubMed Abstract | Publisher Full Text | Free Full Text

11. Allen $\mathrm{E}, \mathrm{Xie} Z$, Gustafson AM, et al.: microRNA-directed phasing during transacting siRNA biogenesis in plants. Cell. 2005; 121(2): 207-21. PubMed Abstract | Publisher Full Text

12. Kuo HF, Chiou TJ: The role of microRNAs in phosphorus deficiency signaling. Plant Physiol. 2011; 156(3): 1016-24.

PubMed Abstract | Publisher Full Text | Free Full Text

13. Rhoades MW, Reinhart BJ, Lim LP, et al.: Prediction of plant microRNA targets. Cell. 2002; 110(4): 513-20.

PubMed Abstract | Publisher Full Tex

14. Schwab R, Palatnik JF, Riester M, et al:: Specific effects of microRNAs on the plant transcriptome. Dev Cell. 2005; 8(4): 517-27. PubMed Abstract | Publisher Full Text

15. Llave C, Xie Z, Kasschau KD, et al: Cleavage of Scarecrow-like mRNA targets directed by a class of Arabidopsis miRNA. Science. 2002; 297(5589): 2053-6. PubMed Abstract | Publisher Full Text

16. Navarro L, Dunoyer P, Jay F, et al.: A plant miRNA contributes to antibacteria resistance by repressing auxin signaling. Science 2006; 312(5772): 436-9. PubMed Abstract | Publisher Full Text

17. Addo-Quaye C, Miller W, Axtell MJ: CleaveLand: a pipeline for using degradome data to find cleaved small RNA targets. Bioinformatics. 2009; 25(1): 130-1. PubMed Abstract | Publisher Full Text | Free Full Text

18. German MA, Pillay M, Jeong DH, et al.: Global identification of microRNA-target RNA pairs by parallel analysis of RNA ends. Nat Biotechnol. 2008; 26(8): 941-6.

PubMed Abstract | Publisher Full Text

19. Shamimuzzaman M, Vodkin L: Identification of soybean seed developmental stage-specific and tissue-specific miRNA targets by degradome sequencing. BMC Genomics. 2012; 13: 310 .

PubMed Abstract | Publisher Full Text | Free Full Text

20. Schmutz J, Cannon SB, Schlueter J, et al:: Genome sequence of the palaeopolyploid soybean. Nature. 2010; 463: 178-83. PubMed Abstract | Publisher Full Text

21. Subramanian S, Fu Y, Sunkar R, et al.: Novel and nodulation-regulated microRNAs in soybean roots. BMC Genomics. 2008:9:160. PubMed Abstract | Publisher Full Text | Free Full Text
22. Lullien V, Barker DG, de Lajudie P, et al.: Plant gene expression in effective and ineffective root nodules of alfalfa (Medicago sativa). Plant Mol Biol. 1987; 9(5): 469-78.

PubMed Abstract | Publisher Full Text

23. Vincent JM: A manual for the practical study of root nodule bacteria. IBP handbook Blackwell Scientific Publications, Oxford, United Kingdom. 1970; (15). Reference Source

24. Graham TL, Graham MY, Subramanian S, et al:: RNAi silencing of genes for elicitation or biosynthesis of 5-deoxyisoflavonoids suppresses race-specific resistance and hypersensitive cell death in Phytophthora sojae infected tissues. Plant Physiol. 2007; 144(2): 728-40.

PubMed Abstract | Publisher Full Text | Free Full Text

25. Collier R, Fuchs B, Walter N, et al.: Ex vitro composite plants: an inexpensive, rapid method for root biology. Plant J. 2005; 43(3): 449-57.

PublMed Abstract| Publisher Full Text

26. Turner M, Adhikari S, Subramanian S: Optimizing stem-loop qPCR assays through multiplexed cDNA synthesis of U6 and miRNAs. Plant Signal Behav. 2013; 8(8).

PubMed Abstract | Publisher Full Text | Free Full Text

27. Varkonyi-Gasic E, Hellens RP: Quantitative stem-loop RT-PCR for detection of microRNAs. Methods Mol Biol. 2011; 744: 145-57. PubMed Abstract | Publisher Full Text

28. Adhikari S, Turner M, Subramanian S: Hairpin priming is better suited than in vitro polyadenylation to generate cDNA for plant miRNA qPCR. Mol Plant. 2013 6(1): 229-31.

PubMed Abstract | Publisher Full Text

29. Livak KJ, Schmittgen TD: Analysis of relative gene expression data using realtime quantitative PCR and the 2(-Delta Delta C(T)) Method. Methods. 2001; 25(4): 402-8.

PubMed Abstract | Publisher Full Text

30. Rapid amplification of '5' complementary DNA ends (5' RACE). Nat Methods. 2005; 2(8): 629-30.

PubMed Abstract | Publisher Full Tex

31. Mao G, Turner M, Yu O, et al:: miR393 and miR164 influence indeterminate but not determinate nodule development. Plant Signaling Behav. 2013; 8(10). PubMed Abstract | Publisher Full Text

32. Vazquez F, Gasciolli V, Crete P, et al:: The nuclear dsRNA binding protein HYL1 is required for microRNA accumulation and plant development, but not posttranscriptional transgene silencing. Curr Biol. 2004 14(4):346-51. PubMed Abstract | Publisher Full Text

33. Guo HS, Xie Q, Fei JF, et al:: MicroRNA directs mRNA cleavage of the transcription factor NAC1 to downregulate auxin signals for arabidopsis lateral root development. Plant Cell. 2005; 17(5): 1376-86. PubMed Abstract | Publisher Full Text | Free Full Text

34. Zhao Y, Yu Y, Zhai J, et al:: The Arabidopsis nucleotidyl transferase HESO1 uridylates unmethylated small RNAs to trigger their degradation. Curr Biol. 2012; 22(8): 689-94.

PubMed Abstract | Publisher Full Text | Free Full Text

35. Turner M, Yu O, Subramanian S: Genome organization and characteristics of soybean microRNAs. BMC Genomics. 2012; 13: 169 PubMed Abstract | Publisher Full Text | Free Full Text

36. Carlsbecker A, Lee JY, Roberts CJ, et al:: Cell signalling by microRNA165/6 directs gene dose-dependent root cell fate. Nature. 2010; 465(7296): 316-21. PubMed Abstract | Publisher Full Text | Free Full Text

37. Liu PP, Montgomery TA, Fahlgren N, et al.: Repression of AUXIN RESPONSE FACTOR 10 by microRNA160 is critical for seed germination and postgermination stages. Plant J. 2007; 52(1): 133-46. PubMed Abstract | Publisher Full Text

38. Li J, Reichel M, Millar AA: Determinants beyond both complementarity and cleavage govern microR159 efficacy in Arabidopsis. PLoS Genet. 2014; 10(3): e1004232.

PubMed Abstract | Publisher Full Text | Free Full Text

39. Udvardi MK, Czechowski T, Scheible WR: Eleven golden rules of quantitative RT-PCR. Plant Cell. 2008; 20(7): 1736-7.

PubMed Abstract | Publisher Full Text | Free Full Text

40. Damodaran S, Adhikari S, Turner M, et al:: Raw data qACE to assay miRNAdirected target cleavage. F1000Research. 2014.

Data Source 


\section{Open Peer Review}

\section{Current Peer Review Status: ? ? ?}

\section{Version 1}

Reviewer Report 12 May 2015

https://doi.org/10.5256/f1000research.5613.r8620

(c) 2015 Millar A. This is an open access peer review report distributed under the terms of the Creative Commons Attribution License, which permits unrestricted use, distribution, and reproduction in any medium, provided the original work is properly cited.

\section{Anthony A. Millar}

Plant Science Division, Research School of Biology, Australian National University, Canberra, ACT, Australia

Here, the authors describe an assay that quantifies miRNA-guided cleavage products. Then, by comparing to the mRNA levels of the corresponding non-cleaved target transcripts, a ratio is obtained that estimates the proportion of transcript present in the cell has been cleaved by the miRNA. They tested this in an overexpression line, a miRNA-deficient mutant, and in an example where an endogenous miRNA is expressed in a tissue specific manner. The discussion nicely points out the advantages and limitations of the approach.

Although the assay represents a relatively straight forward modification of a widely used protocol, modifying it into a quantitative-PCR protocol may enable a number of interesting questions to be addressed. For example, it may give an insight into the efficiency of miRNA-mediated regulation, where it could determine if all equally predicted targets are cleaved as efficiently as one another.

\section{Minor comments}

The authors state in the abstract that qACE can "determine the extent of miRNA regulation for a specific target gene". This method only measures transcript cleavage, but nothing can be inferred about any translational inhibition mechanism, which there is now very strong evidence that many (possibly most) miRNA-target interactions have a translational repression component to it. Maybe this should be mentioned somewhere in the manuscript as it has basically been ignored, and so this method can only measure the efficiency of cleavage but not the "extent of miRNA regulation".

Also in abstract the term "differential cleavage by miR164" makes it sound like the miRNA is cleaving differently in the different tissues, this may turn out to be the case in some examples, but here isn't more likely due to the fact that miR164 is differentially expressed, having a higher abundance in root tissues compared to nodules? I would be careful with the use of that term.

In the discussion; "we demonstrate that both NAC1 and CUC2 had similar levels of increase in hen1-1, but different levels of reduction in miR164-directed cleavage." Maybe the authors should 
be more careful with their claims, as qPCR measurements can vary, and the number of biological reps were not indicated, they did mention "replicate assays" but this seems something different, so how repeatable was this difference?

Competing Interests: No competing interests were disclosed.

I confirm that I have read this submission and believe that I have an appropriate level of expertise to confirm that it is of an acceptable scientific standard, however I have significant reservations, as outlined above.

Reviewer Report 27 April 2015

https://doi.org/10.5256/f1000research.5613.r8479

(c) 2015 Masson P. This is an open access peer review report distributed under the terms of the Creative Commons Attribution License, which permits unrestricted use, distribution, and reproduction in any medium, provided the original work is properly cited.

\section{Patrick Masson}

Department of Genetics, University of Wisconsin-Madison, Madison, WI, USA

This paper describes a method that allows quantification of miRNA-directed cleavage of specific target RNAs in plant tissues. Method validation includes an analysis of target cleavage in miRNA over-expressing tissues and in miRNA-deficient samples (hen1 mutant). Usefulness of the approach is illustrated by the identification of a role for miRNA-directed cleavage in the modulation of nodule-specific GmNAC1-isoform expression in Glycine max.

This quantitative protocol may reveal itself as very useful in experiments aimed at characterizing the role played by miRNAs in the regulation of target gene expression in plants and their contribution to growth, development and response to the environment. However, under its current form, this manuscript suffers from a lack of independent validation of its quantitative output. Such validation should involve a different approach aimed at quantifying the relative levels of miRNA, full-length and cleaved target transcripts in wild type, overexpressing and miRNAdeficient mutants. For instance, a Northern blot analysis of wild-type, miR164-over-expressing and hen 1 plant tissues could be carried out to evaluate relative levels of miR164 as well as full-length AtNAC1 and its miR164-induced cleavage product, and the results compared to those obtained through the qRT-PCR and qAce approaches described in this manuscript. Indeed, we know from the publication by Guo et al. (2005) (referenced in this manuscript) that these various RNAs can be identified and quantified by Northern blot analysis

Competing Interests: No competing interests were disclosed.

I confirm that I have read this submission and believe that I have an appropriate level of expertise to confirm that it is of an acceptable scientific standard, however I have significant reservations, as outlined above. 
Reviewer Report 19 November 2014

https://doi.org/10.5256/f1000research.5613.r6570

(C) 2014 Schwab R. This is an open access peer review report distributed under the terms of the Creative Commons Attribution License, which permits unrestricted use, distribution, and reproduction in any medium, provided the original work is properly cited.

\section{Rebecca Schwab}

Center for Plant Molecular Biology, University of Tübingen, Tübingen, Germany

\section{Technical comments:}

1. The 'proof' that the method can reliably quantify miRNA target cleavage products is based on inferences from previous reports - that increased cleavage is expected when the corresponding miRNA is over-expressed, and that reduced cleavage is to be seen in miRNA biosynthetic mutants such as hen1.

An adequate validation should however include an independent methodology, such as regular northern blots for miRNA targets. This is easily done when choosing targets that are reasonably stable. Quantification of the resulting bands (full length and cleaved) will serve as an independent proof of concept.

2. It would be helpful to add a couple of words during the results section about the design of qACE primers and to what extent they require optimisation (overlap adapter/target). Sort of a guideline.

3. Also, the RCT value should be explained a bit better during the results section.

4. Stability of miRNA target cleavage products is an issue - sometimes they are easily detected, sometimes they are not. This is mentioned in the discussion, but should come up before as it is a major point of consideration for the design of the experiments.

\section{Materials and Methods:}

1. What tissues were used for RT experiments?

2. Which primers were used to over-express miR164 in soybean?

\section{Other:}

I somewhat disagree with the statement '...quantification of the extent of regulation of specific target genes by miRNA is crucial for proper understanding of their biological roles.'

To investigate the biological roles of miRNAs, quantifying (and spatially/temporally visualising) target protein levels is very important. Quantifying the extent of miRNA-directed cleavage contributing to target protein levels are however very interesting for mechanistic studies of miRNA-mediated gene regulation.

Sentences are sometimes phrased very generally. Since miRNA-directed cleavage is not a main issue in animals, 'plants' can come up already in the beginning of sentences. 
Competing Interests: No competing interests were disclosed.

I confirm that I have read this submission and believe that I have an appropriate level of expertise to confirm that it is of an acceptable scientific standard, however I have significant reservations, as outlined above.

The benefits of publishing with F1000Research:

- Your article is published within days, with no editorial bias

- You can publish traditional articles, null/negative results, case reports, data notes and more

- The peer review process is transparent and collaborative

- Your article is indexed in PubMed after passing peer review

- Dedicated customer support at every stage

For pre-submission enquiries, contact research@f1000.com 